Virqotin Najiyah. 2017. Pengaruh Perilaku Konsumen Terhadap Minat Berkunjung Ke Pantai Serang Kabupaten Blitar.

Journal Viabel Pertanian. (2018), 12 (1) 9-17

\title{
PENGARUH PERILAKU KONSUMEN TERHADAP MINAT BERKUNJUNG KE PANTAI SERANG KABUPATEN BLITAR
}

\author{
Virqotin Najiyah $^{1)}$, Tri Kurniastuti ${ }^{2)}$, Erlin Widya Fatmawati ${ }^{2)}$ \\ ${ }^{1)}$ Mahasiswa Program Studi Agroteknologi Fakultas Pertanian \\ ${ }^{2)}$ Dosen Program Studi Agroteknologi Fakultas Pertanian \\ Universitas Islam Balitar \\ Blitar \\ E-mail: fyeqotin@gmail.com
}

\begin{abstract}
Serang beach is one of the beaches in Blitar Regency. Visits to Serang Beach attractions are influenced by various factors. In this study the factors studied to determine the influence of visiting interest to Serang Beach is promotional factors, economic factors, factors of infrastructure and psychological factors. Sampling in this research is by accidental sampling method, in which the researcher has the freedom to choose who the consumer is met to be sampled, with the number of respondents as many as 100 people. Data analysis was done by using multiple linier regression analysis method, data processing was done by SPSS Statistics 16 for Windows program. The result of the research shows that promotion factor, economic factor, facility factor and psychological factors significantly (together) have an influence on the interest of visiting Serang Beach, and psychological factor is the most dominant factor influencing the interest to visit Serang Beach tourism object.
\end{abstract}

Keywords: Serang Beach, consumer behavior and factors influencing interest in visiting.

\section{PENDAHULUAN}

Sektor andalan dalam menunjang pembangunan nasional adalah sektor pariwisata. Karena dari sektor pariwisata dapat diperoleh beberapa manfaat yaitu meningkatkan devisa negara, memperluas lapangan pekerjaan serta meningkatkan kesejahteraan masyarakat (Novi Puspita P, 2008). Sektor pariwisata ini sangat diharapkan oleh pemerintah bisa menjadi pengganti pemasok devisa utama setelah terdegradasinya peran migas (I Gusti N Bagus P dkk, 2015). Indonesia memiliki begitu banyak tempat pariwisata yang bisa menjadi andalan Negara untuk memperkenalkan Indonesia, seperti pariwisata Pantai Kuta Bali, Raja Ampat Papua yang sudah terkenal hingga mancanegara. Blitar merupakan sebuah daerah yang terletak di bagian selatan Provinsi Jawa Timur, Indonesia. Daerah ini terletak sekitar $167 \mathrm{~km}$ sebelah barat daya Surabaya dan $80 \mathrm{~km}$ sebelah barat Malang. Blitar terkenal sebagai tempat dimakamkannya presiden pertama Republik Indonesia, Ir. Soekarno. Selain disebut sebagai Kota Proklamator dan Kota Patria, Blitar juga disebut sebagai Kota Peta (pembela tanah air) kerena dibawah kepemimpinan Soeprijadi, Laskar Jepang untuk pertama kalinya pada tanggal 14 Februari 1945 yang menginspirasi timbulnya perlawanan menuju kemerdekaan di daerah lain. Selain itu, Blitar juga merupakan sebuah daerah yang mempunyai segudang tempat 
Virqotin Najiyah. 2017. Pengaruh Perilaku Konsumen Terhadap Minat Berkunjung Ke Pantai Serang Kabupaten Blitar.

Journal Viabel Pertanian. (2018), 12 (1) 9-17

wisata yang sangat indah diantaranya seperti wisata pantai, wisata alam, serta wisata sejarah. (Aneka Wisata Bahari, Artikel).

Salah satu objek wisata yang ada di Kabupaten Blitar adalah Pantai Serang yang terletak di Desa serang Kecamatan Panggungrejo Kabupaten Blitar. Di Pantai Serang ini selain menikmati deburan ombak di pantai, wisatawan juga bisa menikmati hijaunya pepohonan yang rindang dan sejuk yang jauh dari kata panasnya pantai pada umumnya. Di Pantai Serang ini juga sudah ada wahana permainan, yaitu ATV, yang bisa disewa oleh wisatawan di Pantai Serang ini. Setiap harinya Pantai Serang ini tidak pernah luput dari kunjungan para wisatawan bahkan bukan pada saat hari libur tetap ada wisatawan yang datang ke Pantai Serang ini. Di Pantai Serang ini juga menjadi salah satu tempat favorit untuk menikmati matahari terbenam. Dari segala keunikan pantai ini menjadikan banyaknya pengunjung yang berkali-kali kembali ke Pantai serang ini. Dari paparan yang telah ada, maka penelitian ini mengambil judul "Pengaruh Perilaku Konsumen terhadap Minat Berkunjung ke Pantai Serang Kabupaten Blitar". Tujuan dalam penelitian ini adalah sebagai berikut: Ingin menganalisis dan mengetahui pengaruh perilaku konsumen yang terdiri dari faktor promosi, faktor ekonomi, faktor sarana prasarana dan faktor psikologis mempunyai pengaruh yang signifikan terhadap minat berkunjung ke Pantai Serang Kabupaten Blitar dan ingin mengetahui faktor yang terdiri dari faktor promosi, faktor ekonomi, faktor sarana prasarana dan faktor psikologis mana yang paling dominan mempengaruhi perilaku konsumen terhadap minat berkunjung ke Pantai Serang Kabupaten Blitar.

\section{METODE PENELITIAN}

Populasi penelitian ini adalah seluruh pengunjung wisata Pantai Serang Kabupaten Blitar yang berkunjung ke objek wisata Pantai Serang ini. Adapun metode pengambilan sampel dalam penelitian ini adalah metode convenience sampling atau accidental sampling, di mana peneliti memiliki kebebasan untuk memilih siapa saja konsumen yang ditemui untuk dijadikan sampel. Pengambilan sampel dalam penelitian ini adalah pengunjung yang melakukan kunjugan ke wisata Pantai Serang Kabupaten Blitar.

Penentuan jumlah sampel pada penelitian ini menggunakan 100 responden dari hasil pendapat Roscoe dalam buku Sugiono (2006: 80) yaitu ukuran sample yang layak dalam penelitian adalah antara 30 - 500 responden. Untuk memungkinkan para responden menjawab dalam berbagai tingkatan bagi setiap pertanyaan, digunakan skala liketr, yaitu berupa kuesioner yang memiliki 5 skor. Metode pengambilan data yang digunaka dalam penelitian ini adalah kuesioner, wawancara dan observasi.

\section{Uji Validitas}

Uji Validitas Item atau butir kuesioner pada penelitian ini dilakukan dengan menggunakan software aplikasi SPSS 16 for windows. Dalam proses uji validitas ini, akan digunakan Uji Korelasi Pearson Product Moment. Masing-masing variable X dan Y dalam penelitian ini harus memiliki korelasi (r) dengan skor total masing-masing variabel $\geq \mathrm{r}$ tabel. Jika ada salah satu saja variable $\mathrm{X}$ maupun $\mathrm{Y}$ yang memiliki korelasi $(\mathrm{r})<\mathrm{r}$ tabel, artinya item atau butir kuesioner penelitian ini tidak valid dan perlu untuk merubah isi item atau butir kuesioner dengan item atau butir kuesioner yang baru (Seta Basri,2012). 
Virqotin Najiyah. 2017. Pengaruh Perilaku Konsumen Terhadap Minat Berkunjung Ke Pantai Serang Kabupaten Blitar.

Journal Viabel Pertanian. (2018), 12 (1) 9-17

\section{Uji Reabilitas}

Uji reliabilitas ini dilakukan pada taraf signifikasi a sebesar 0,05. Instrument dapat dikatakan reliable bila nilai Cronbach's Alpha lebih besar dari r tabel. Namun ada juga teori lain yang menyatakan jika nilai Cronbach's Alpha harus lebih besar dari 0,60 baru dapat dipastikan bahwa instrument tersebut reliable. Pada penelitian ini uji reliabilitas data diolah dengan menggunakan software aplikasi SPSS 16 for Windows (Sahid Raharjo, 2014).

\section{Uji Asumsi Klasik}

Analisis regresi linier berganda memerlukan beberapa asumsi agar model layak digunakan, asumsi-asumsi yang digunakan dalam penelitian ini adalah sebagai berikut:

\section{a. Uji Normalitas}

Pada uji normalitas dalam penelitian ini adalah sebagai penguji data variabel bebas dan data variabel terikat pada persamaan regresi yang dihasilkan berdistribusi normal atau berdistribusi tidak normal. Persamaan regresi dikatakan baik jika mempunyai data variabel bebas dan variabel terikat berdistribusi normal atau normal sama sekali (Danang, 2014:130).

\section{b. Uji Multikolinearitas}

Uji multikolinearitas digunakan sebagai upaya untuk menentukan ada dan tidaknya korelasi yang sempurna atau mendekati hubungan yang sempurna. Menurut Hasan (2008:281) non multikolinearitas adalah hubungan antara variabel bebas yang satu dengan variabel yang lain dalam model regresi tidak terjadi hubungan yang sempurna ataupun hubungan yang mendekati sempurna. Kekuatan hubungan korelasi diukur berdasarkan skala $\mathrm{r}$ adalah 0 sampai denagn 1 (berlaku untuk $\mathrm{r}$ positif maupun negatif) (Danang Sunyoto, 2014:116).

\section{c. Uji Heteroskedastisitas}

Menurut Hasan (2002) heteroskedastisitas berarti variasi variabel tidak sama untuk semua pengamatan. Pada heteroskedastisitas, kesalahan yang terjadi random (acak) tetapi memperlihatkan hubungan yang sistematis sesuai dengan besarnya satu atau lebih variabel bebas. Heteroskedastisitas yang ada dalam regresi dapat menyebabkan:

- Penaksir (estimator) yang diperoleh menjadi tidak efisien, hal itu disebabkan variansnya sudah tidak minim lagi (tidak efisien)

- Kesalahan baku koefisien regresi akan terpengaruh, sehingga memberikan indikasi yang salah dan koefisien determinasi memperlihatkan daya penjelasan terlalu besar (Danang, 2014:117).

\section{d. Uji Autokorelasi}

Uji autokorelasi digunakan untuk menguji regresi linier ada korelasi antara kesalahan pengganggu pada periode $\mathrm{t}$ dengan kesalahan pada periode $\mathrm{t}-1$ (sebelumnya). Jika terjadi korelasi maka artinya ada problem autokorelasi. Deteksi adanya autokorelasi 
Virqotin Najiyah. 2017. Pengaruh Perilaku Konsumen Terhadap Minat Berkunjung Ke Pantai Serang Kabupaten Blitar.

Journal Viabel Pertanian. (2018), 12 (1) 9-17

dengan melihat besarnya Durbin Watson yang secara umum dapat diambil patoakan (Danang, 2014:116).

Angka D-W di bawah -2 berarti ada autokorelasi positif.

Angka D-W di bawah -2 sampai +2 berarti tidak ada autokorelasi.

Angka D-W di atas +2 berati ada autokorelasi negative.

\section{e. Persamaan Regresi Linier Berganda}

Analisis ini digunakan untuk mengetahui seberapa besar pengaruh variabel bebas yaitu faktor promosi, faktor ekonomi, faktor sarana prasaran dan faktor psikologis terhadap variabel terikat yaitu minat berkunjung. Persamaan regresi linier berganda adalah sebagai berikut:

$$
\mathrm{Y}=\mathrm{a}+\mathrm{b} 1 \mathrm{X} 1+\mathrm{b} 2 \mathrm{X} 2+\mathrm{b} 3 \mathrm{X} 3+\mathrm{b} 4 \mathrm{X} 4+\mathrm{e}
$$

\section{f. Uji F}

Uji F digunakan untuk mengetahui pengaruh antara variabel independen (faktor promosi, faktor ekonomi, faktor sarana prasarana dan faktor psikologis) terhadap variabel dependen (minat berkunjung) secara bersama-sama (Danang Sunyoto, 2014: 119). Uji F bisa dengan membandingkan $\mathrm{F}$ tabel dengan $\mathrm{F}$ hitung. Nilai $\mathrm{F}$ tabel harus $<\mathrm{F}$ hitung agar Ho ditolak dan Ha diterima (Oetarjo, 2013).

\section{g. Uji t}

Uji t digunakan untuk mengetahui ada tidaknya hubungan atau pengaruh yang berarti (signifikan) antara variabel independen ( faktor promosi, faktor ekonomi, faktor sarana prasarana dan faktor psikologis) secara parsial terhadap variabel dependen (minat berkunjung) (Danang Sunyoto, 2014: 118).

Ha: $\mathrm{X} 1=\mathrm{X} 2=\mathrm{X} 3=\mathrm{X} 4=0$, artinya tidak ada pengaruh yang signifikan antara variabel independen ( faktor promosi, faktor ekonomi, faktor sarana prasarana dan faktor psikologis) secara parsial terhadap variabel dependen (minat berkunjung).

Ho: $\mathrm{X} 1=\mathrm{X} 2=\mathrm{X} 3=\mathrm{X} 4 \neq 0$, artinya ada pengaruh yang signifikan antara variabel independen ( faktor promosi, faktor ekonomi, faktor sarana prasarana dan faktor psikologis) secara parsial terhadap variabel dependen (minat berkunjung).

\section{KEADAAN UMUM LOKASI PENELITIAN}

Pantai Serang merupakan pantai yang terletak di pesisir Pantai Selatan atau di Samudra Hindia, tepatnya di Desa Serang, Kecamatan Panggungrejo Kabupaten Blitar, kurang lebih $45 \mathrm{Km}$ arah barat daya Kota Blitar dan jarak tempuhnya kurang lebih 1,5 jam. Pantai ini memiliki hamparan pasir yang putih dan landai serta bibir pantai yang cukup panjang dengan ombak yang tidak terlalu tinggi, sehingga memudahkan wisatawan untuk bermain air laut (Anonim, 2014). Pantai Serang ini terdiri dari tiga kawasan, selain pantai utama melewati jalan setapak ke barat terdapat pantai lain yang dipisahkan oleh 
Virqotin Najiyah. 2017. Pengaruh Perilaku Konsumen Terhadap Minat Berkunjung Ke Pantai Serang Kabupaten Blitar.

Journal Viabel Pertanian. (2018), 12 (1) 9-17

bukit. Pantai ini memiliki pasir putih namun pantainya tidak seluas pantai utama. Melanjutkan perjalanan ke barat dengan mendaki bukit, masih ada pantai yang ketiga. Pantainya lebih luas dari kedua pantai sebelumnya dan ombaknya pun tidak terlalu besar (Smanta's Traveller, 2015).

Di Pantai Serang ini memiliki ombak terbaik pada bulan Maret dan Agustus tiap tahunnya, ombaknya bisa mencapai 4 sampai dengan 12 meter anginnya pun cukup kencang (Madani, 2016). Selain ombak yang begitu mengagumkan, Pantai Serang ini juga memiliki atraksi wisata, yaitu ritual tradisional Larung Sesaji yang dilakukan setiap tanggal 1 Suro. Larung sesaji adalah tradisi atau kebudayaan masyarakat untuk mengucapkan rasa syukur karena tradisi ini lahir sebelum masyarakat memahami konsep ketuhanan yang sebenarnya, maka rasa syukur mereka terjemahkan dengan memberikan sesuatu kepada penguasa dengan cara menghanyutkan atau melepas atau melarung (Smanta Traveller, 2015).

\section{HASIL DAN PEMBAHASAN}

\section{Uji Validitas}

Uji validitas digunakan untuk mengukur valid dan tidak validnya suatu kuesioner. Dalam penelitian ini harus memiliki nilai korelasi (r) dengan skor total masing-masing variabel $\geq r$ tabel agar intrumen kuesioner ini bisa dikatakan valid.

\begin{tabular}{cccc}
\hline Variabel & Item & r hitung & r tabel \\
\hline Faktor Promosi (X1) & x 1.1 & $\mathbf{0 . 7 2 6}$ & 0.4227 \\
x 1.2 & $\mathbf{0 . 7 2 6}$ & 0.4227 \\
Faktor Ekonomi & x1.3 2.1 & $\mathbf{0 . 7 5 8}$ & 0.4227 \\
(X2) & $\mathbf{0 . 5 9 3}$ & 0.4227 \\
& x2.2 & $\mathbf{0 . 6 3 9}$ & 0.4227 \\
Faktor Sarana & x 2.3 & $\mathbf{0 . 5 9 3}$ & 0.4227 \\
Prasarana (X3) & x3.1 & $\mathbf{0 . 5 7 9}$ & 0.4227 \\
& x3.2 & $\mathbf{0 . 7 7 4}$ & 0.4227 \\
Faktor Psikologis & x3.3 3.4 & $\mathbf{0 . 5 3 3}$ & 0.4227 \\
(X4) & x4.1 & $\mathbf{0 . 5 6 8}$ & 0.4227 \\
Minat Berkunjung & x 4.2 & $\mathbf{0 . 7 4 6}$ & 0.4227 \\
(Y) & y.1 & $\mathbf{0 . 7 7 4}$ & 0.4227 \\
& y.2 & $\mathbf{0 . 7 9 4}$ & 0.4227 \\
& y.3 & $\mathbf{0 . 6 6 1}$ & 0.4227 \\
& y.4 & $\mathbf{0 . 7 8 9}$ & 0.4227 \\
& y.5 & $\mathbf{0 . 6 6 2}$ & 0.4227 \\
\hline
\end{tabular}

\section{Uji Reabilitas}

Uji reliabilitas adalah alat untuk mengukur suatu kuisioner yang merupakan indikator dari variabel atau konstruk. Butir kuesioner dikatakan reliabel atau andal 
Virqotin Najiyah. 2017. Pengaruh Perilaku Konsumen Terhadap Minat Berkunjung Ke Pantai Serang Kabupaten Blitar.

Journal Viabel Pertanian. (2018), 12 (1) 9-17

apabila jawaban seseorang terhadap kuesioner adalah konsisten. Dalam penelitian ini untuk menentukan kuesioner reliabel atau tidak reliabel menggunakan alpha cronbach. Kuesioner reliabel jika alpha cronbach $>0.60$ dan tidak reliabel jika sama dengan atau dibawah 0.60. Dalam penelitian ini menghasilkan nilai alpha cronbach sebesar 0.941 yang lebih besar dari 0.60 artinya data kuesioner ini reliabel dan bisa digunakan sebagai penelitian.

\section{Uji Asumsi Klasik}

a. Uji Multikolinieritas

Uji asumsi klasik jenis ini diterapkan untuk analisis regresi berganda yang terdiri atas dua atau lebih variabel bebas/independent variable, di mana akan diukur tingkat asosiasi pengaruh antar variabel bebas tersebut melalui besaran koefisien korelasi. Dalam penelitian ini menggunakan menggunakan besaran nilai toleransi $(\alpha)$ dan nilai variance inflation factor (VIF). Variabel bebas mengalami multikolinieritas jika $\alpha$ hitung $<\alpha$ dan VIF hitung $>$ VIF dan variabel bebas tidak mengalami multikolinieritas jika $\alpha$ hitung $>\alpha$ dan VIF hitung < VIF (Danang, 2014).

\begin{tabular}{cccccc}
\hline Model & $\mathrm{B}$ & $\mathrm{t}$ & Sig. & Tolerance & VIF \\
\hline (Constant) & 18.966 & 13.732 & .000 & & \\
faktor promosi & -.158 & -2.289 & .024 & .720 & $\mathbf{1 . 3 8 8}$ \\
faktor ekonomi & .258 & 2.111 & .037 & .740 & $\mathbf{1 . 3 5 2}$ \\
faktor sarana & .110 & 2.014 & .047 & .708 & $\mathbf{1 . 4 1 3}$ \\
prasarana & .288 & 2.714 & .008 & .776 & $\mathbf{1 . 2 8 8}$ \\
faktor psikologis & & &
\end{tabular}

\section{b. Uji Heteroskedastisitas}

Dalam persamaan regresi berganda perlu diuji mengenai sama atau tidak sama varians dari residual dari observasi yang satu dengan observasi yang lain (Danang, 2014). Uji heteroskedastisitas brarti adanya varian dalam model yang tidak sama (konstan). Dalam uji ini menggunakan Normal P-P Plot of Regression Standardized Residual dengan ketentuan titik-titik menyebar di bawah dan di atas sumbu $\mathrm{Y}$, dan tidak mempunyai pola yang teratur semua, artinya data ini tidak mengalami heteroskedastisitas.

\section{c. Uji Normalitas}

Pada penelitian ini uji normalitas data menggunakan uji kolmogornov smirnov dan menggunakan kurva regression residual terstandarisasi pada hasil uji pada program SPSS 16 for windows. Dengan menggunakan kurva regression residual terstandarisasi harus membentuk gambar lonceng. Uji kolmogornov smirnov dengan membandingkan nilai kolmogornov smirnov hitung harus lebih besar dari pada kolmogornov smirnov tabel.

Dalam penelitian ini menghasilkan nilai kolmogornov smirnov sebesar 2.896 yang lebih besar dari nilai kolmogornov smirnov tabel yaitu 0.134. Pada kurva regression residual terstandarisasi membentuk gambar lonceng yang artinya data ini normal dan siap untuk digunakan untuk penelitian. 
Virqotin Najiyah. 2017. Pengaruh Perilaku Konsumen Terhadap Minat Berkunjung Ke Pantai Serang Kabupaten Blitar.

Journal Viabel Pertanian. (2018), 12 (1) 9-17

\section{d. Uji Autokorelasi}

Pada uji autokorelasi dalam penelitian ini menggunakan cara uji Durbin Watson dengan menggunakan program SPSS 16 for windows. Pada uji autokorelasi ini menghasilkan nilai Durbin Watson sebesar 1.683 yang lebih besar dari nilai Durbin Watson tabel yaitu 1.5922, yang artinya data ini tidak mengalami autokorelasi dan siap untuk digunakan sebagai penelitian.

\section{Persamaan Regresi Linier Berganda}

Untuk menganalisis data yang diperoleh dari hasil penelitian, digunakan analisis regresi linear berganda. Untuk mempermudah proses estimasi dan untuk menghindari adanya kemugkinan kesalahan terjadi, maka proses estimasi dalam penelitian ini menggunakan komputer program SPSS Statistics 16 for Windows.

\begin{tabular}{cccccc}
\hline Model & $\mathrm{B}$ & $\mathrm{t}$ & Sig. & Tolerance & VIF \\
\hline (Constant) & $\mathbf{1 8 . 9 6 6}$ & 13.732 & .000 & & \\
faktor promosi & $\mathbf{- . 1 5 8}$ & -2.289 & .024 & .720 & 1.388 \\
faktor ekonomi & $\mathbf{. 2 5 8}$ & 2.111 & .037 & .740 & 1.352 \\
faktor sarana & $\mathbf{. 1 1 0}$ & 2.014 & .047 & .708 & 1.413 \\
prasarana & $\mathbf{. 2 8 8}$ & 2.714 & .008 & .776 & 1.288 \\
faktor psikologis & SPSS & Statis 16 for Windows & pada tobel dias
\end{tabular}

Dari hasil perhitungan SPSS Statistics 16 for Windows pada tabel diatas, persamaan regresi yang dapat dibentuk adalah sebagai berikut:

$$
\mathrm{Y}=18.966-0.158 \mathrm{X} 1+0.258 \mathrm{X} 2+0.110 \mathrm{X} 3+0.288 \mathrm{X} 4+\mathrm{e}
$$

Nilai koefisien determinasi berganda ( $\mathrm{R}$ square) sebesar 0.221, hal ini menunjukkan bahwa minat berkunjung ke objek wisata Pantai Serang dipengaruhi oleh faktor promosi (X1), faktor ekonomi (X2), faktor sarana prasarana (X3) dan faktor psikologis (X4) adalah sebesar $22 \%$ sedangkan sisanya yaitu $78 \%$ dipengaruhi oleh variabel lain diluar penelitian.

\section{Uji F}

Untuk menunjukkan apakah semua variabel bebas yaitu faktor promosi (X1), faktor ekonomi (X2), faktor sarana prasarana (X3) dan faktor psikologis (X4) mempunyai pengaruh signifikan secara bersama-sama terhadap variabel terikat yaitu minat berkunjung (Y) digunakan uji F. Hasil pengujian yang dilakukan pada program SPSS Statistics 16 for Windows dengan membandingkan F tabel < F hitung. Dalam penelitian ini menghasilkan nilai $F$ sebesar 6.727 yang $>$ dari $F$ tabel 3.09, artinya semua variabel bebas yaitu faktor promosi (X1), faktor ekonomi (X2), faktor sarana prasarana (X3) dan faktor psikologis (X4) mempunyai pengaruh signifikan secara bersama-sama terhadap variabel terikat yaitu minat berkunjung $(\mathrm{Y})$.

\section{Uji t}

Untuk mengetahui apakah semua variabel bebas yaitu faktor promosi (X1), faktor ekonomi (X2), faktor sarana prasarana (X3) dan faktor psikologis (X4) mempunyai 
Virqotin Najiyah. 2017. Pengaruh Perilaku Konsumen Terhadap Minat Berkunjung Ke Pantai Serang Kabupaten Blitar.

Journal Viabel Pertanian. (2018), 12 (1) 9-17

pengaruh yang signifikan secara parsial terhadap variabel terikat yaitu minat berkunjung ke objek wisata Pantai Serang (Y) digunakan uji t. Hasil pengujian yang dilakukan pada program SPSS Statistics 16 for Windows dengan membandingkan $\mathrm{t}$ tabel $<\mathrm{t}$ hitung.

\begin{tabular}{cccc}
\hline Model & $\mathrm{t}$ hitung & $\mathrm{t}$ tabel & Sig. \\
\hline (Constant) & $\mathbf{1 3 . 7 3 2}$ & 1.29053 & .000 \\
faktor promosi & $\mathbf{- 2 . 2 8 9}$ & 1.29053 & .024 \\
faktor ekonomi & $\mathbf{2 . 1 1 1}$ & 1.29053 & .037 \\
faktor sarana & $\mathbf{2 . 0 1 4}$ & 1.29053 & .047 \\
prasarana & $\mathbf{2 . 7 1 4}$ & 1.29053 & .008 \\
faktor psikologis &
\end{tabular}

\section{KESIMPULAN DAN SARAN}

\section{Kesimpulan}

Berdasarkan penelitian yang telah dilakukan dapat diambil kesimpulan dari hasil penelitian ini yaitu sebagai berikut:

a. Variabel bebas yang terdiri dari faktor promosi (X1), faktor ekonomi (X2), faktor sarana prasarana (X3) dan faktor psikologis (X4) mempunyai pengaruh yang signifikan secara simultan (bersama-sama) terhadap minat berkunjung (Y) ke objek wisata Pantai Serang Kabupaten Blitar karena besar F hitung lebih besar dari F tabel (F hitung sebesar 6.727 > F tabel sebesar 3.09).

b. Variabel bebas faktor psikologis (X4) merupakan faktor yang paling dominan yang mempengaruhi minat berkunjung (Y) ke objek wisata Pantai Serang Kabupaten Blitar karena nilai t hitung faktor psikologis (X4) (2.714) adalah yang paling besar dibandingkan dengan variabel bebas faktor promosi (X1) (- 2.289), faktor ekonomi (X2) (2.111) dan faktor sarana pra-sarana (X3) (2.014).

\section{Saran}

\section{Saran dalam penelitian ini adalah sebagai berikut:}

a. Untuk pengelola objek wisata Pantai Serang lebih memperhatikan lagi tentang kebersihan Pantai, karena masih banyak pengunjung yang merasa pantai ini kurang bersih. Alat kebersihannya juga masih kurang seperti tempat sampah yang masih jarang ditemui. Dan juga tentang akses jalan menuju objek wisata ini masih perlu dibenahi. Pengelola objek wisata Pantai Serang bisa bekerjasama dengan pemerintah daerah untuk membangun akses jalan yang lebih baik agar bisa menarik wisatawan lebih banyak lagi dari berbagai luar kota.

b. Untuk pemerintah daerah, sebaiknya lebih memperhatikan tentang objek wisata yang jauh dari pusat pemerintahan, karena objek wisata yang baik dan memiliki fasilitas yang memadai akan menarik pengunjung wisatawan dari berbagai luar daerah yang banyak dan bisa menjadi pendapatan tambahan untuk pemerintah daerah. 
Virqotin Najiyah. 2017. Pengaruh Perilaku Konsumen Terhadap Minat Berkunjung Ke Pantai Serang Kabupaten Blitar.

Journal Viabel Pertanian. (2018), 12 (1) 9-17

\section{DAFTAR PUSTAKA}

AA. Anwar Prabu Mangkunegara. 1988. Perilaku Konsumen. PT. Eresco: Bandung.

Anonim. Artikel. Definisi Menurut para Ahli: Pengertian Wisata. www.definisimenurutparaahli.com/pengertian-wisata/.

Basri, Seta. 2012. Uji Validitas dan Reliabilitas Instrumen Penelitian dengan SPSS. http://setabasri01.blogspot.co.id/2012/04/uji-validitas-dan-reliabilitas-item.html. Seta Basri Menulis Terus.

Gusti, I Ngurah B. Pradnyana, I Ketut Arnawa dan I Made Tamba. 2015. Faktor-faktor yang Mempengaruhi Kunjungan Wisatawan di Taman Hutan Raya Ngurah Rai. Agribisnis. Universitas Mahasaraswati Denpasar: Bali.

Madani. 2016. Membangun Peradaban Berbasis Potensi Desa Wisata Serang Kabupaten Blitar. http://beritamadani.co.id/2016/06/05/membangun-peradaban-berbasispotensi-desa-wisata-serang-kabpaten-blitar/. 06 Juni 2016.

Puspita, Novi P. 2008. Artikel. Pengembangan Sektor Kepariwisataan dalam Menunjang Perluasan Kesempatan Kerja di Kabupaten Kediri. www.researchgate.net/researcher/56269267_Novi_Puspita_P.

Raharjo, Sahid. 2014. Artikel. Uji Reliabilitas Data dengan SPSS. http://www.konsistensi.com/2013/04/uji-reliabilitas-data-dengan-spss.html. 3 Februari 2014.

Sugiyono. 2006. Statistika untuk Penelitian, cetakan ke sembilan. ALFABETA: Bandung. 2008. Metode Penelitian Kuantitatif, Kualitatif dan R\&D. Alfabeta: Bandung.

Sunyoto, Danang. 2014. Praktik Riset Perilaku Konsumen. CAPS (Center of Aca-demic Publishing Service): Yogyakarta.

Sunyoto, Danang. 2015. Perilaku Konsumen dan Pemasaran. CAPS (Center of Academic Publishing Service): Yogyakarta.

Traveller, Smanta's. 2015. Pantai Serang Icon Wisata Baru Di Blitar. http://travellersman1 talun.blogspot.co.id/2015/08/pantai-serang-icon-wisata-barudi-blitar.html.

Wisata, Aneka Bahari. 39 Tempat Wisata Terbaik di Blitar Jawa Timur. www.anekalokasiwisata.com/39-tempat-wisata-terbaik-di-blitar-jawa-timur/. Artikel.

Wisata, Tribun. 2016. Pengertian Wisata, Kepariwisataan, Wisatawan dan Objek Wisata. www.tribunwisata.com/2016/09/pengertin-wisata-kepariwisataan-wisatawan-danobjek-wisata.html?m=1. Sabtu, 24 September 2016. 